\title{
AGRICULTURA URBANA E PERIURBANA E OS CONFLITOS DA ESPECULAÇÃO IMOBILIÁRIA EM ALFENAS-MG
}

\author{
Rodrigo Clemente GOIS \\ Flamarion Dutra ALVES ${ }^{2}$ \\ Evânio dos Santos BRANQUINHO
}

\section{Resumo}

Nos tempos contemporâneos é cada vez mais evidente a necessidade de organizar os espaços urbanos e rurais em virtude das novas relações sociais e suas interações com o meio ambiente. Alfenas como uma cidade média vêm apresentando um aumento no número de loteamentos residenciais nos últimos anos, ocupando algumas áreas que eram destinadas a pecuária e agricultura. Sendo assim o presente artigo tem como objetivos organizar informações dos produtores agrícolas urbanos e periurbanos afim de espacializar e caracterizar essas atividades, analisar o avanço da especulação imobiliária sobre essas propriedades e como o cultivo orgânico é uma alternativa viável para a produção urbana e periurbana mitigando problemas socioambientais resultantes deste avanço. liária.

Palavras-chave: Relação campo-cidade. Espaço periurbano. Especulação imobi-

\section{Abstract \\ Urban and periurban agriculture and the conflicts of real estate speculation in Alfenas-MG}

In contemporary times it is increasingly evident the need to organize urban and rural spaces by virtue of the new social relations and their interactions with the environment. Alfenas as a middle town have been showing an increase in the number of residential subdivisions in recent years, occupying some areas that were intended for livestock and agriculture. Thus, the present article aims to organize information from urban and periurban agricultural producers in order to characterize these activities, analyze the progress of real estate speculation on these properties and how organic farming is a viable alternative for urban and periurban production, mitigating problems resulting from this progress.

Key words: Countryside-city relation. Peri-urban space. Real estate speculation.

\footnotetext{
1 Universidade Federal de Alfenas - MG, Graduando em Geografia. Endereço: Rua Cunhambebe 76, Centro, Ubatuba - SP. E-mail: rdobeca4@gmail.com

2 Universidade Federal de Alfenas - MG, Professor Adjunto IV e líder do Grupo de Estudos Regionais e Socioespaciais-GERES. Endereço: Av. Jovino Fernandes Sales, 2600. UNIFAL-MG, Bairro Santa Clara, Alfenas-MG. CEP: 37133-840. E-mail: dutrasm@yahoo.com.br

3 Universidade Federal de Alfenas - MG, Professor Associado I e membro do Grupo de Estudos Regionais e Socioespaciais-GERES. Endereço: Av. Jovino Fernandes Sales, 2600. UNIFAL-MG, Bairro Santa Clara, Alfenas-MG. CEP: 37133-840. E-mail: esbranquinho@uol.com.br
} 


\section{INTRODUÇÃO}

Nos tempos contemporâneos é cada vez mais evidente a necessidade de organizar os espaços urbanos e rurais em virtude das novas relações sociais e suas interações com o meio ambiente. A agricultura tem uma função crucial que é o abastecimento das cidades e da manutenção dos espaços rurais, e, para que isso ocorra, os produtores necessitam de auxilio técnico qualificado e políticas públicas para estruturar sua produção e reprodução dos modos de vida. A agricultura urbana (AU) nos últimos anos tem sido uma das formas encontradas pela população urbana para superar as crises econômicas e de mercado de trabalho dos centros urbanos (MOUGEOT, 2005). E nos espaços próximos ao perímetro urbano das cidades, a agricultura periurbana tem sofrido pressões para continuidade das atividades devido a especulação imobiliária e valorização do espaço urbano.

Alfenas como uma cidade média vêm apresentando um aumento no número de loteamentos residenciais nos últimos anos, ocupando algumas áreas que eram destinadas a pecuária e agricultura familiar. Essa expansão do perímetro urbano proporciona uma supervalorização do metro quadrado, alterando as funções socioeconômicas do lugar tendo como uma das consequências a pressão sobre a população local, praticamente forçando-os a migrar para as zonas periféricas da cidade, abandonando assim a atividade agrícola, ou ainda, se distanciando mais da cidade na zona rural.

Tendo isto posto, o presente trabalho visa responder algumas questões como: qual seria a participação da agricultura urbana e periurbana no abastecimento interno de Alfenas? E como se dá essa produção? Existe algum tipo de política pública para a produção ou comercialização desses produtos? E ainda, a especulação imobiliária tem pressionado os agricultores familiares no espaço periurbano de Alfenas?

Sendo assim o presente artigo tem como objetivos organizar informações dos agricultores urbanos e periurbanos da região oeste de Alfenas afim de espacializar e caracterizar essas atividades, além de verificar se existe a produção orgânica e como ela está estruturada e por fim, analisar o avanço da especulação imobiliária sobre as propriedades periurbanas.

\section{METODOLOGIA}

O presente trabalho foi realizado no município de Alfenas, localizado na Mesorregião Sul/Sudoeste do Estado de Minas Gerais (Figura 1) e na microrregião que leva o mesmo nome do município. Apresenta uma altitude máxima de 888 metros acima do nível do mar e possui uma população estimada em 79.222 habitantes (IBGE, 2016) com um clima tipicamente tropical de altitude.

A pesquisa se desenvolveu na região oeste de Alfenas, devido a instalação do campus da Universidade Federal de Alfenas- Unidade Santa Clara em 2011, que ocasionou uma forte transformação no espaço em seu entorno, atraindo investimentos imobiliários e consequentemente a especulação sobre áreas urbanas e rurais. Com isso, deu-se a abertura de vários loteamentos no lugar antes caracterizado por atividades agropecuárias. 

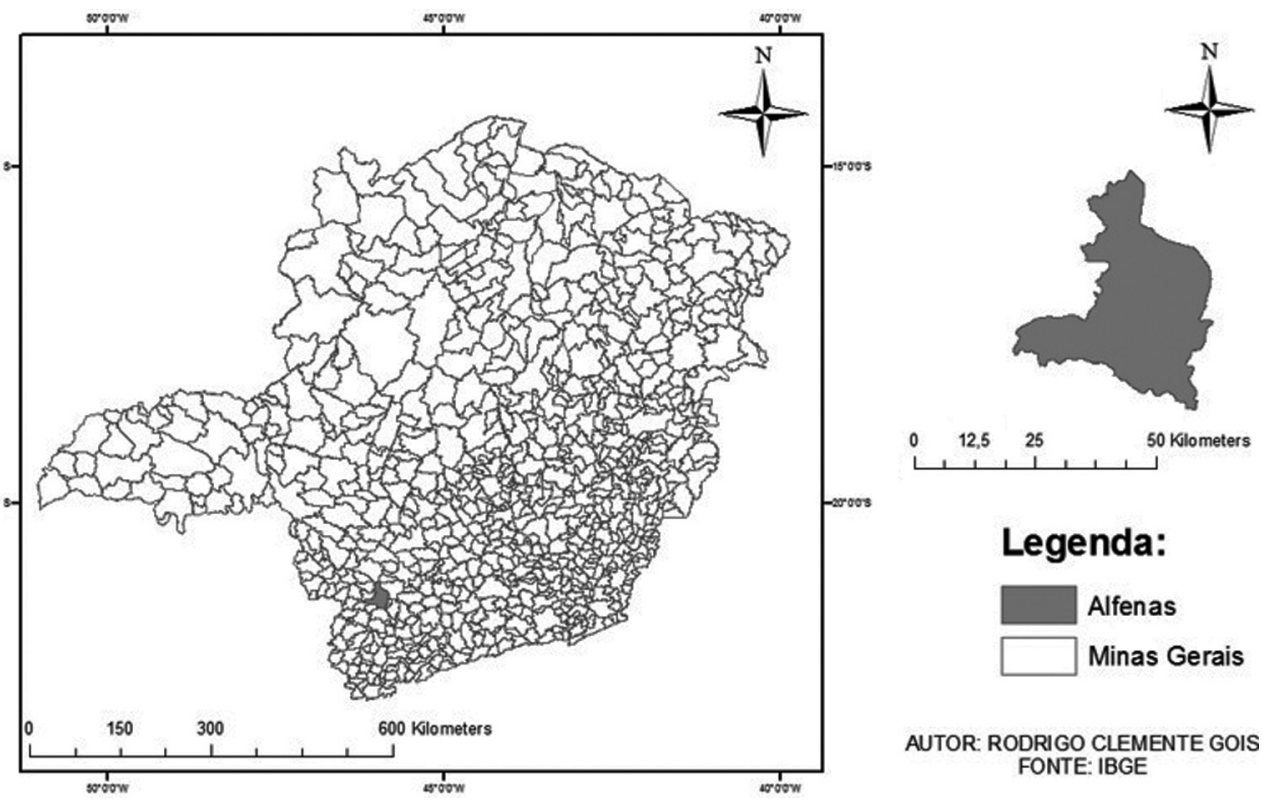

AUTOR: RODRIGO CLEMENTE GOIS FONTE: IBGE

Figura 1 - Localização do município de Alfenas-MG

Para entender o comportamento dessa dinâmica no espaço local, foram realizadas visitas a campo, sendo elas para aplicação de entrevista quantitativa e qualitativa com os produtores agrícolas da região oeste de Alfenas, próximos a UNIFAL-MG, seguindo os critérios de definição da agricultura urbana (AU) segundo Mougeot (2005) e espaços perirubanos conforme Vale (2005), aliado a essas bases teóricas, foi discutida a questão da valorização do espaço urbano e da produção do espaço, para meIhor entendimento das relação campo-cidade.

As entrevistas buscaram obter informações sobre características socioeconômicas e ambientais, como idade, origem do produtor, a cidade de origem, - local do cultivo, área da propriedade, tipo, modelo e destino da produção, se tem outra remuneração além da agricultura, a forma de captação da água, a situação da propriedade, se recebe algum tipo de auxílio governamental, os incentivos que seriam ideais para a produção, e como ele percebe o futuro da produção e das hortas nos espaços perirubanos frente a especulação imobiliária em Alfenas.

A seleção dos produtores foi baseada por dois critérios: o primeiro se baseou nas propriedades próximas a Universidade Federal de Alfenas campus Santa Clara que sofrem com a especulação imobiliária e abertura de diversos loteamentos residenciais. O segundo critério é a proximidade das propriedades com cursos de água e se esses eram destinados para as hortas, pois aparentemente esses afluentes não apresentam boa qualidade da água, passando pela mancha urbana de Alfenas e sendo impactados por dejetos e esgoto residencial.

Após esses critérios, foram selecionados 16 proprietários entrevistados, sendo 10 residentes no perímetro urbano e 6 no espaço periurbano. Após a aplicação das entrevistas, montou-se um banco de dados e espacializou-se essas propriedades usando uma imagem obtida no Google Earth Pró, sobrepondo com a resposta de localização, tipo de produção, influência da especulação imobiliária e suas respectivas posi- 
ções geográficas; o processamento desses dados foi feito no programa de geoprocessamento ArcMap 10.2.

\section{AGRICULTURA URBANA E PERIURBANA: DEFINIÇÕES, ESTRATÉGIAS DE DESENVOLVIMENTO E A VALORIZAÇÃO DO ESPAÇO URBANO}

A agricultura urbana ( $A U)$ na atualidade é uma realidade presente em muitas áreas urbanas mundiais independentemente da escala de produção. Nos últimos anos, a $\mathrm{AU}$ tem sido uma das formas encontradas pelos cidadãos urbanos a superarem a atual conjuntura econômica e a instabilidade do mercado de trabalho nos centros urbanos. As hortas urbanas com o enfoque da AU é uma forma de agricultura planejada e é realizada pelos benefícios econômicos, sociais e ambientais que proporciona.

Aquino e Assis (2007) lembram que:

A associação quase instantânea que é feita entre agricultura e meio rural pode levar a uma impressão de incompatibilidade entre agricultura e meio urbano. Entretanto, a agricultura urbana não é uma atividade recente e, de alguma forma, sempre se expressou nas áreas urbanas, mesmo que timidamente. (AQUINO, ASSIS, 2007, p. 137).

A produção de alimentos em perímetros urbanos, tem alguns aspectos positivos em termos econômicos e sociais, pois as famílias que cultivam hortas em terrenos vazios ou nos lotes residenciais, economizam com supermercado e feiras, podendo aplicar o dinheiro em outras atividades, além de produzir alimentos mais saudáveis, com menos ou nada de agrotóxicos. Em muitos casos, o excedente da produção é comercializado em feiras ou na própria residência, contribuindo para a renda familiar. Com base nesses argumentos, Mougeot (2005) delineia a agricultura urbana e periurbana:

As definições mais usuais da agricultura urbana se baseiam nos seguintes determinantes: - tipos de atividade econômica; - localização intra-urbana ou periurbana; • tipos de áreas onde ela é praticada; • sua escala e sistema de produção; • as categorias e subcategorias de produtos (alimentícios e não alimentícios); e • a destinação dos produtos, inclusive sua comercialização (MOUGEOT, 2005, p. 3).

O mesmo autor ainda discorre mais sobre como distinguir a agricultura urbana com a agricultura rural, dizendo que:

Não é a localização, urbana, que distingue a $A U$ da agricultura rural, e sim o fato de que ela está integrada e interage com o ecossistema urbano. Essa integração com o ecossistema urbano não é captada na maioria das definições do conceito de $A U$, e menos ainda é desenvolvida em termos operacionais. Ainda que a natureza das concentrações urbanas e de seus sistemas de abastecimento de alimentos tenha mudado, a necessidade da AU de interagir adequadamente com o resto da cidade, por um lado, e com a produção rural e as importações, por outro, continua sendo tão decisiva hoje como era há milhares de anos (MOUGEOT, 2005, p. 6). 
A forma ideal para produção de hortas urbanas e periurbanas é aquela com uso restrito de insumos químicos, para valorizar essa atividade que está inserida no contexto urbano, e assim ser uma produção diferenciada da convencional e que promova qualidade de vida em termos ambientais e socioeconômicos. Aquino e Assis (2007) concordam com essa premissa:

Nesse sentido é que a agroecologia é considerada especialmente apropriada para o entorno urbano, posto que sistemas de produção orgânicos com foco agroecológico caracterizam-se como um instrumento interessante para viabilização da agricultura em pequena escala, em regime de administração familiar, tanto em sistemas de parcelas individuais como em explorações associativas, posto que a baixa dependência de insumos externos facilita a adoção dessa forma de produção por esse tipo de agricultor (AQUINO; ASSIS, 2007, p. 140).

As famílias que praticam a $\mathrm{AU}$ melhoram a qualidade de vida permitindo a diversidade alimentar, uma vez que fornece, na maioria dos casos alimentos sadios e de baixo custo, utilizando na sua produção compostos e fertilizantes orgânicos para combater pragas e doenças. A agroecologia traz com sigo uma forma de garantir uma agricultura urbana que ajude nos problemas sociais, ambientais e econômicos de um município, garantindo a segurança alimentar dos produtos gerados por ela.

Entretanto, a valorização do solo urbano é cada vez mais crescente e cada espaço é disputado por inúmeros atores sociais, e a pressão para tornar áreas rurais (periurbanas) em urbanas é muito grande, por conta dos interesses públicos em aumentar a área de arrecadação de impostos e estar associado ao desenvolvimento, e também os interesses privados em tornar esse espaço em mercadoria, criando loteamentos e condomínios residenciais.

O processo de produção da valorização da terra é distinto por se tratar de lógicas de uso diferenciada, na cidade ela se baseia pela localização, infraestrutura, circulação das mercadorias de fácil acesso (renda diferenciada), já no campo a fertilidade, o acesso a água, circulação são os principais fatores de valorização como Freitas e Vieira Neto (2005) apontam:

Como se trata de uma mercadoria diferenciada das demais, pelo fato de a terra não ser considerada um capital, mas sim um equivalente de capital, seu processo de valorização não é decorrente de forma direta de trabalho, mas sim das formas de como se dão a sua apropriação e uso. É um processo de valorização que se manifesta de diversas formas no campo e na cidade. Na cidade, a formação da renda decorre principalmente da formação de uma renda diferencial, enquanto no campo a fertilidade da terra também contribui para sua formação" (FREITAS; VIEIRA NETO, 2005, p. 2).

É interessante analisar como é a produção da valorização da terra, seja ela no urbano ou rural, que o aspecto que define o aumento ou queda do valor se dá na forma de ocupação, ou seja, depende do interesse do capital e sua definição da expansão urbana sobre o território, inclusive o Estado vai intervir na oferta de serviços públicos dependendo de qual classe ocupar aquela determinada área.

Para os proprietários de terra e empreendedores é muito interessante à produção de loteamentos, parcelamento da terra, mas para o Estado isso implica diversos tipos de investimentos em serviços urbanos e infraestrutura. Normalmente ocorre a 
abertura desses novos loteamentos simultaneamente com o esvaziamento urbano na zona central como lembra Santoro e Bonduki (2009) que dizem:

A expansão da franja urbana significa para as prefeituras a necessidade de extensão de serviços urbanos como as redes de saneamento, iluminação pública e coleta de resíduos sólidos; a demanda pela edificação de novos equipamentos como escolas, postos de saúde, creches, áreas verdes, um aumento nos custos de varrição e manutenção dos espaços públicos, a necessidade de expansão das redes de transporte coletivo; entre tantos outros. Muitas vezes, a abertura de novos parcelamentos periféricos ocorre simultaneamente com dinâmicas de esvaziamento populacional, subutilização e deterioração do parque edificado de áreas centrais, esvaziando áreas onde o Estado já investiu e infraestruturou. Além disto, novos parcelamentos periféricos quase nunca estão vinculados à escassez de imóveis urbanos, sendo comum verificar casos onde há diversos lotes vazios ao mesmo tempo que a produção de novos lotes é intensa. Dinâmicas que seguem a lógica do mercado imobiliário capitalista (SANTORO; BONDUKI, 2009, p. 2).

Os problemas sociais que essas dinâmicas geram talvez não apareçam em primeiro momento, mas não podemos ignorar, pois são graves as consequências geradas como a pressão nos recursos hídricos, alta especulação imobiliária e com isso a expulsão dos proprietários rurais e também nos bairros periféricos. De fato o processo de urbanização gera ganhos significativos para os donos de terra dos loteamentos para classes alta e média e sobretudo, os investidores e construtoras, e para os agricultores periurbanos é um processo de resistência e exclusão, frente os interesses dos setores públicos e privados em expandir o perímetro urbano e os negócios gerados nesse processo.

\section{RESULTADOS}

A especulação imobiliária e a crescente valorização do espaço urbano de Alfenas, fazem com que algumas atividades econômicas e pessoas estejam em situação de conflito dos interesses. Conforme Ribeiro (2017) entre 2010 e 2016 foram criados 15 loteamentos residenciais em Alfenas. Desde a instalação do campus da Universidade Federal de Alfenas em 2011 no bairro Santa Clara (figura 2) houve uma crescente transformação do espaço em seu entorno e a criação de 5 loteamentos. A área situada na região oeste de Alfenas, periférica, foi valorizada e algumas atividades agropecuárias do espaço perirubano, tendem a desaparecer ao longo do tempo.

A produção agropecuária no espaço urbano e periurbano de Alfenas é diversa e tem função de subsistência e de comercialização. Das 10 residências pesquisadas na área urbana, 7 produzem hortaliças, mandioca, milho, frutas ou criação de galinhas, sendo a produção basicamente para o consumo da família, entretanto 3 produzem para comercialização nas feiras livres da cidade de Alfenas, no próprio local e para supermercados e restaurantes (Figura 3), além de criação de peixes em açudes abastecidos pelas águas do córrego que atravessa o perímetro urbano, ou seja, a agricultura urbana desempenha um papel importante para as famílias que cultivam, bem como para o abastecimento do mercado local de alimentos. 


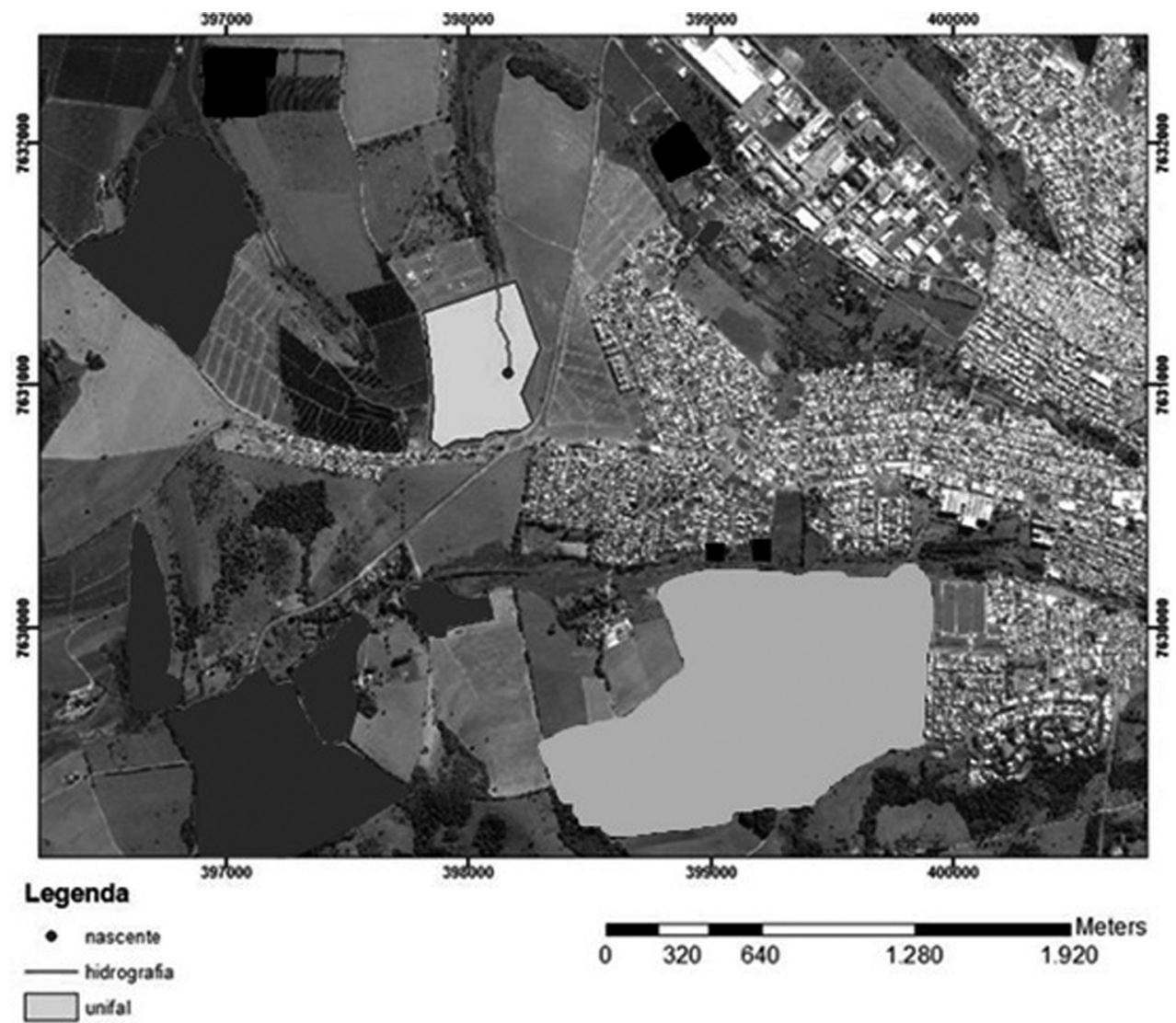

Propriedades

Produção
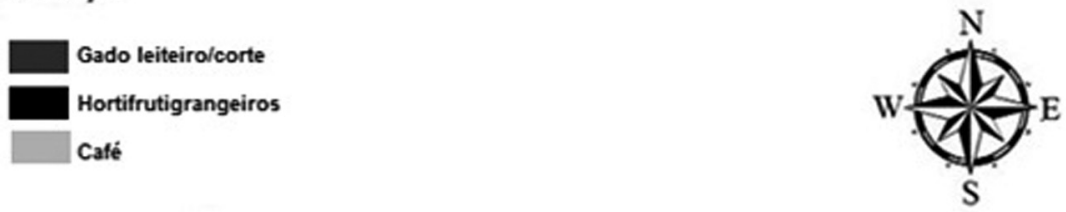

Figura 2 - Localização das propriedades

e o tipo de cultivo em Alfenas-MG 
Já no espaço periurbano, a presença de criação de gado leiteiro e de corte é mais significativa, tendo sua produção destinada para empresas de laticínios da cidade, além da produção de hortaliças que abastecem os supermercados e restaurantes. Nas 6 propriedades empregam-se 15 trabalhadores para manutenção das atividades.

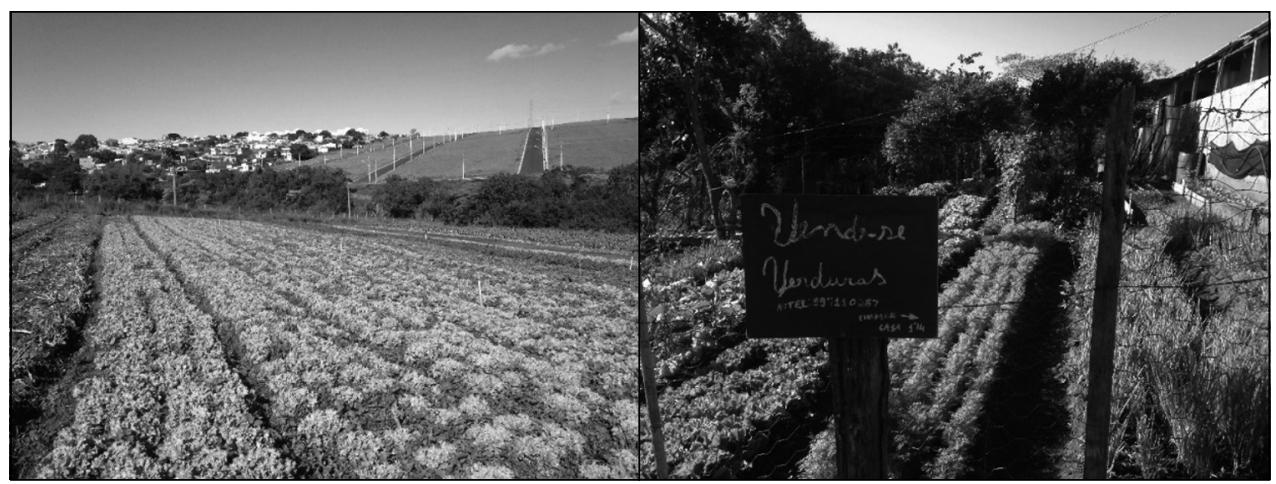

Figura 3 - Produção de hortaliças da agricultura urbana em Alfenas-MG

Com base no tipo de produção, as práticas orgânicas ainda estão longe de serem as predominantes (Figura 4), tendo apenas 4 produtores da agricultura urbana que implementam esse modo de produção.

A produção de gado para corte utiliza o método convencional, sendo que o gado fica um período em confinamento comendo apenas ração industrial, período de engorda, e outro período o gado é solto para pastagem. No laticínio a produção é convencional e o leite é fornecido por produtores de Alfenas que utilizam ração e pasto.

Dois pequenos produtores com base na produção orgânica e se encaixam na agricultura urbana; o primeiro visa abrir um pesqueiro na propriedade e tem uma plantação de diversas espécies de árvores frutíferas que também são utilizadas para a preservação da mata ciliar do córrego que passa pelo terreno, com isso foi prometido para ele a licença para utilizar e preservar aquela área pela prefeitura municipal. O segundo tem uma plantação de hortaliças e também utiliza um modelo orgânico de produção; ele relata que não vai ter condições de manter muito tempo a produção na propriedade por ela ser pequena e a pressão imobiliária ser forte (Figura 5).

Conforme entrevistas realizadas sobre a percepção da pressão da especulação imobiliária e o avanço do perímetro urbano, apenas uma propriedade relata que não sente essa pressão e que acha que a produção vai ser mantida durante vários anos.

O proprietário da monocultura de café próxima ao perímetro urbano relatou que a propriedade já tem dois parcelamentos da terra em forma de loteamentos residenciais, sendo o primeiro com as vendas totalmente concluídas e todos os terrenos construídos, o segundo loteamento, as vendas ainda estão em andamento, mas a infraestrutura já está pronta, sendo os dois loteamentos de alto padrão.

A propriedade que produz hortaliças de forma orgânica e tem criação de gado leiteiro localizada bem próxima ao campus da UNIFAL-MG Santa Clara, afirma que parte da propriedade já foi destinada para criação de um loteamento (Figura 6), sendo este voltado para camadas mais populares. 


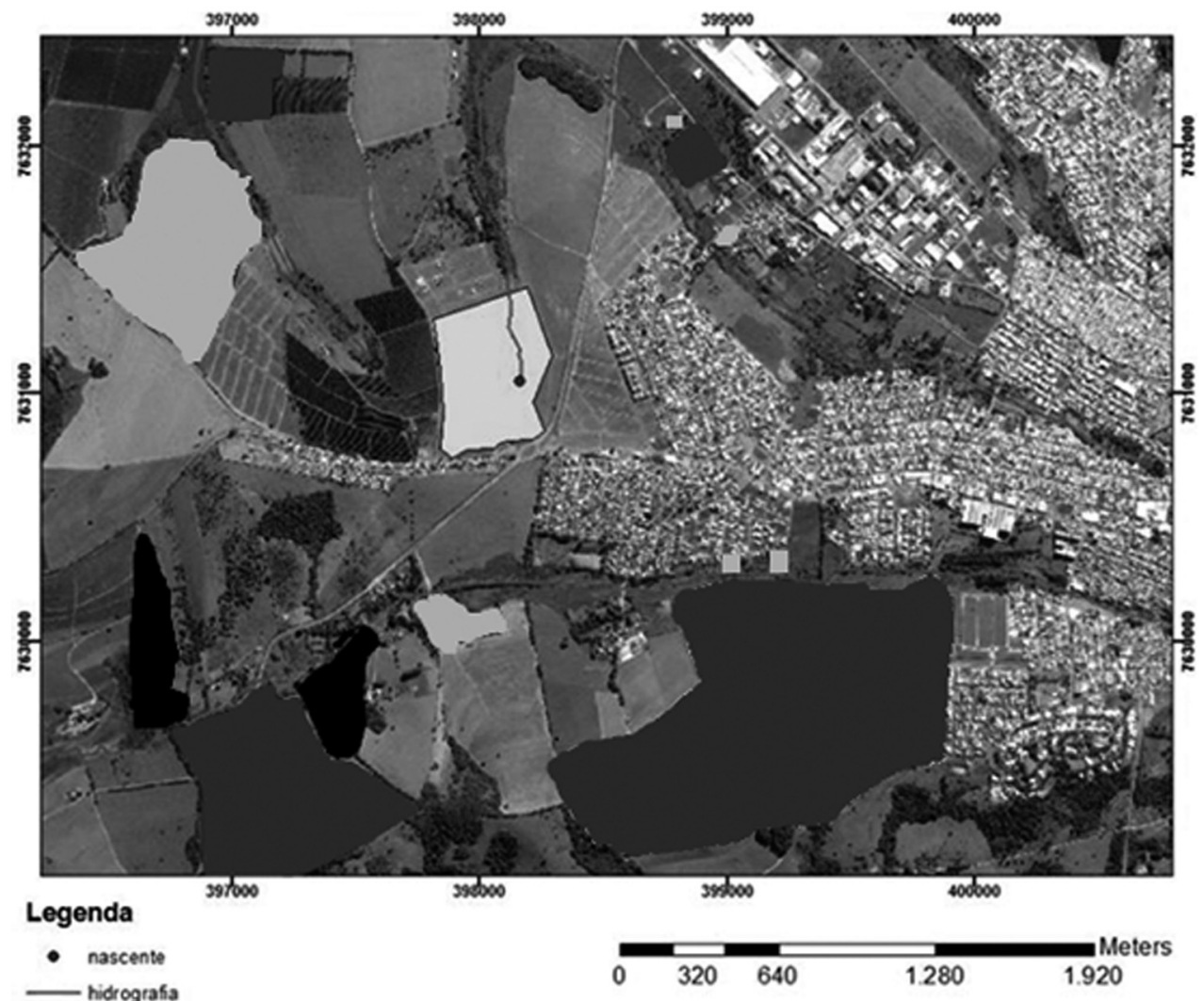

\begin{tabular}{|l}
$\square$ unifal \\
Propriedades
\end{tabular}

Modelo de produção

\begin{tabular}{|l}
\hline Convencional \\
Misto \\
Orgånico
\end{tabular}

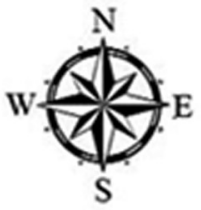

Figura 4 - Modelo de produção da agricultura urbana e periurbana de Alfenas-MG 


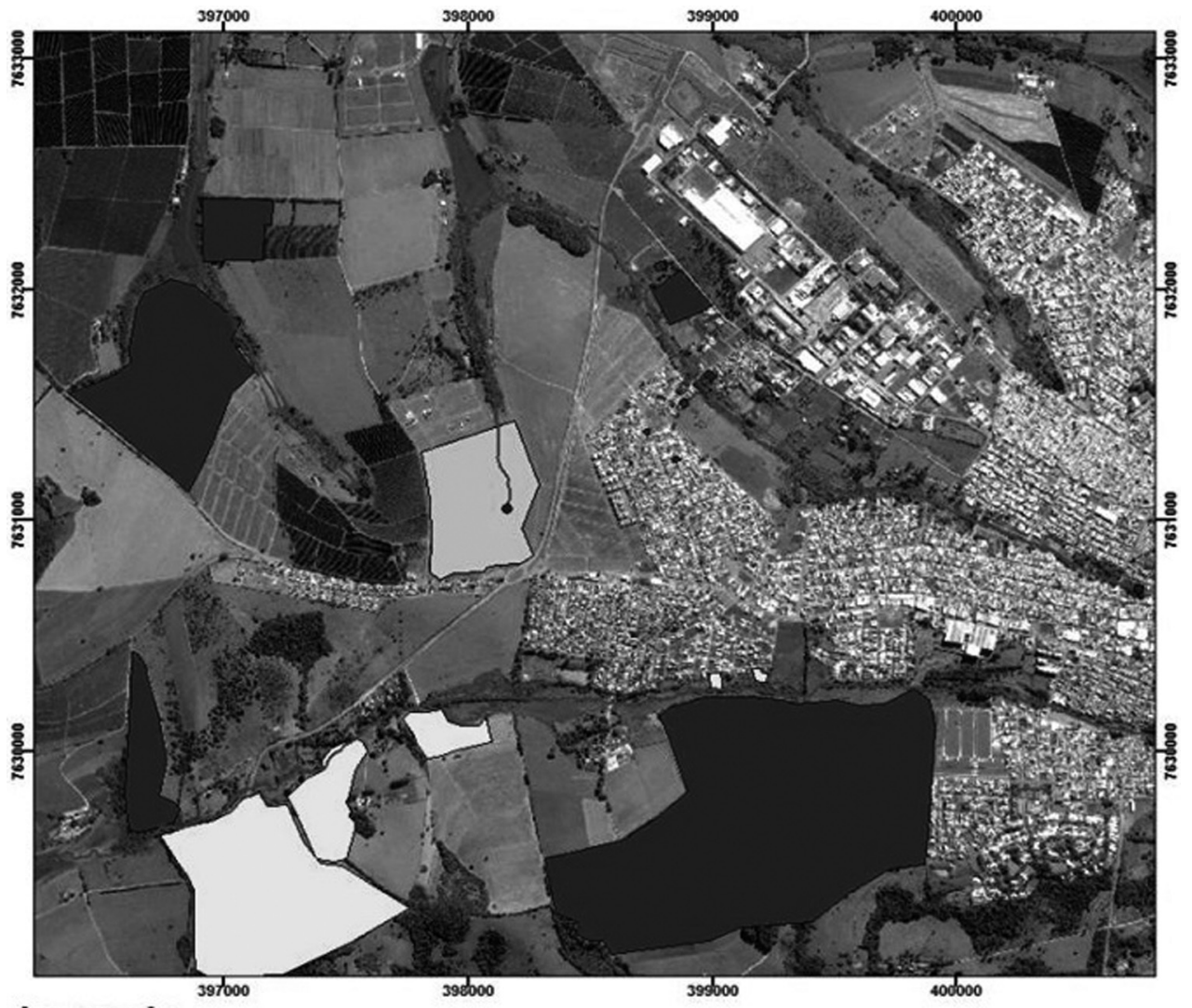

\section{Legenda}

- nascente

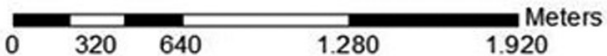

hidrografia

unifal

\section{Propriedades}

Especulação_imobiliária
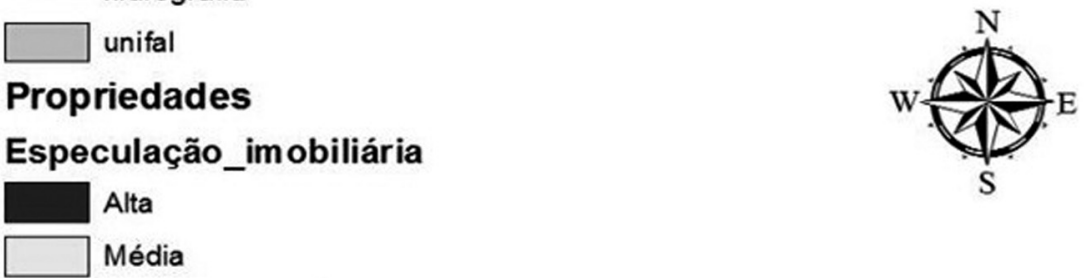

Figura 5 - Percepção da especulação imobiliária sobre o espaço perirubano de Alfenas-MG 


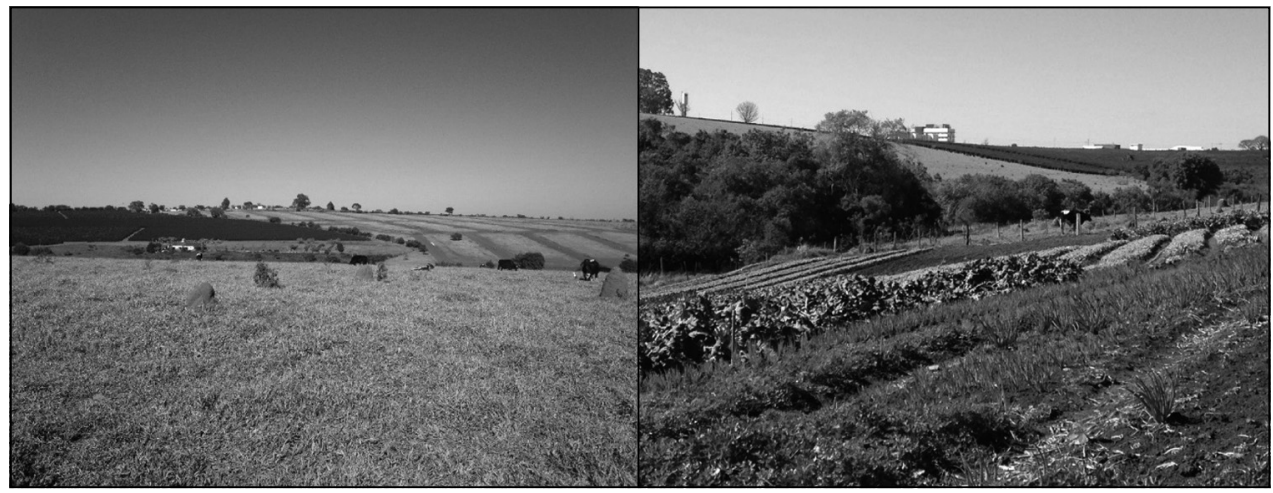

Figura 6 - Presença de loteamentos próximos ao espaço periurbano de Alfenas-MG

A abertura do loteamento aproveita a presença da universidade e eleva a pressão do mercado imobiliário sobre as propriedades rurais no entorno, esse fato é elevado ao analisar a situação das propriedades rurais do espaço periurbano, pois todas são arrendadas ou há presença de caseiros.

\section{CONSIDERAÇÕES FINAIS}

A agricultura urbana e periurbana são importantes fontes de alimentos para o abastecimento local na cidade de Alfenas e desempenham uma função relevante na economia. Esses produtores são muitas vezes negligenciados pelo poder público devido à falta de assistência e planejamento com sua produção.

Pode-se averiguar que a produção orgânica ainda não é uma prática entre os agricultores urbanos e periurbanos, e essa forma de produção poderia ser uma alternativa de renda extra ao agregar valor nos produtos comercializados, além de elevar a qualidade dos alimentos e promover qualidade de vida.

Entretanto, esses produtores estão cada vez mais susceptíveis a pressão imobiliária que é imposta pelo mercado e agentes públicos que autorizam a criação demasiada de loteamentos residenciais na cidade de Alfenas, conforme aponta Ribeiro (2017). A produção de alimentos entre hortaliças e leite, sobretudo, serão as mais afetadas e comprometerá o mercado local, pois serão menos produtores que fornecerão alimentos, podendo encarecer o produto final, além de aumentar o número de trabalhadores desempregados.

A presença do campus da UNIFAL, promoveu ações dialéticas no território alfenense, a contribuição no que tange a qualidade de vida e promoção sociocultural, até mesmo a supervalorização do espaço no seu entorno, que está coloca os produtores periurbanos em conflito com os interesses do capital imobiliário. 


\section{REFERÊNCIAS}

AQUINO, A. M. de; ASSIS, R. L. de. Agricultura Orgânica em Áreas Urbanas e Periurbanas com Base na Agroecologia. Ambiente \& Sociedade. Campinas v. $x, n$. 1, p. 137 - 150, 2007.

BRANCO, M.C; ALCÂNTARA, F.A. Hortas urbanas e periurbana: o que nos diz a literatura brasileira? Horticultura brasileira, Brasília, v. 29, n. 3, p. 421 - 428, 2011.

CAIADO, A. S. C.: SANTOS, S. M.M. dos. Fim da dicotomia rural-urbano? Um olhar sobre processos socioespaciais. São Paulo em Perspectiva, São Paulo, v. 3-4, n. 17 , p. $115-124,2003$.

FREITAS, C. A. L. L; VIEIRA NETO, A. O processo de valorização do solo urbano: formação e apropriação da mais-valia espacial. Colóquio Marx e Engels, v.4, Anais... Campinas, p.1-10, 2005.

MADALENO, I. M. Políticas de apoio à agricultura urbana em Lisboa e Presidente Prudente. Revista de Agricultura Urbana. Instituto Tropical, Lisboa, n. 4, 2001.

MOURA, J.A; FERREIRA, W.R; LARA, L.B.L.S. Agricultura urbana e periurbana. Mercator, Fortaleza, v. 12, n. 27, p 69-80, 2013.

MOTA, D. M. da; SCHMITZ, H. Pertinência da categoria rural para análise social. Ciências Agrotécnicas, v. 26, n. 2, 392-399, 2002.

MOUGEOT, L. J.A. Agricultura Urbana - conceito e definição. Revista de Agricultura Urbana, Ottawa, Canadá, v. 1, n. 1, p. 1 - 8, 2005.

RIBEIRO, S. M; et al. Agricultura urbana agroecológica - estratégia de promoção da saúde e segurança alimentar e nutricional. Revista Brasileira de Promoção Saúde, Fortaleza, v.25(3), 381-388, 2012.

RIBEIRO, A.A.L. Produção e valorização do espaço urbano: o caso dos novos loteamentos de Alfenas-MG. Trabalho de conclusão de curso (Geografia). Universidade Federal de Alfenas, Alfenas, 2017.

SANTOS, M. Por uma outra Globalização. São Paulo: Record, 2000.

SANTORO, P. F; BONDUKI N. O desafio do parcelamento do solo a partir do periurbano: composição do preço da terra na mudança de uso de solo rural para urbano. Encontro da Associação Nacional de Pós-Graduação e Pesquisa em Planejamento Urbano e Regional, v.13, Anais... p. 1-25, Florianópolis, 2009.

SEVILLA, E; GUSMÁN. Uma estratégia de sustentabilidade a partir da Agroecologia. Agroecologia e Desenvolvimento Rural Sustentável. Porto Alegre, v. 2, n. 1, p. 35 - 45, 2010.

VALE, A.R. Expansão urbana e plurifuncionalidade no espaço periurbano do município de Araraquara (SP). Tese de doutorado (Geografia). Universidade Estadual Paulista, Rio Claro, 2005. 